\title{
Postoperative Hypofractionated Radiation Therapy in Prostate Carcinoma: A Systematic Review
}

\author{
GIAMBATTISTA SIEPE ${ }^{1}$, MILLY BUWENGE ${ }^{1}$, NAM P. NGUYEN ${ }^{2}$, GABRIELLA MACCHIA ${ }^{3}$, \\ FRANCESCO DEODATO $^{3}$, SAVINO CILLA ${ }^{4}$, GIAN C. MATTIUCCI ${ }^{5}$, ILARIA CAPOCACCIA ${ }^{1}$, \\ SILVIA CAMMELLI ${ }^{1}$, ALESSANDRA GUIDO $^{1}$, ALESSANDRA ARCELLI ${ }^{1}$, \\ MARIA NTRETA ${ }^{1}$, SARA GUERRI $^{6 *}$ and ALESSIO G. MORGANTI ${ }^{1 *}$ \\ ${ }^{1}$ Radiation Oncology Center, Department of Experimental, Diagnostic and Specialty Medicine - \\ DIMES, S. Orsola-Malpighi Hospital, University of Bologna, Bologna, Italy; \\ ${ }^{2}$ Department of Radiation Oncology, Howard University College of Medicine, Washington, DC, U.S.A.; \\ ${ }^{3}$ Radiotherapy Unit, Fondazione "Giovanni Paolo II", Catholic University of Sacred Heart, Campobasso, Italy; \\ ${ }^{4}$ Medical Physic Unit, Fondazione "Giovanni Paolo II", Catholic University of Sacred Heart, Campobasso, Italy; \\ ${ }^{5}$ Radiation Oncology Department, Università Cattolica del Sacro Cuore, Rome, Italy; \\ ${ }^{6}$ Department of Experimental and Specialty Medicine (DIMES), \\ Division of Radiology S. Orsola - Malpighi Hospital, University of Bologna, Bologna, Italy
}

\begin{abstract}
Background/Aim: A systematic review on toxicity, local control $(L C)$, overall survival $(O S)$, and biochemical relapse-free survival (bRFS) after postoperative hypofractionated radiotherapy (HFRT) on prostate cancer $(P C a)$ was performed. Materials and Methods: Based on the PRISMA methodology, studies reporting clinical results after adjuvant or salvage HFRT were included. Results: A total of 1,208 patients from 17 eligible studies were included. Median follow-up was 30 months. No case of severe acute gastrointestinal (GI) toxicity was recorded. Grade $\geq 3$ acute genitourinary $(G U)$ toxicity ranged between $0 \%$ and $3 \%$. Different rates of grade $\geq 2$ late $G I$ (range $=0-8.7 \%$ ) and $G U$ (range $=0-66 \%$ ) toxicity were recorded. Encouraging results on LC, OS, and bRFS were reported. Conclusion: Acute toxicity does not seem to be increased in patients receiving postoperative HFRT, but the results of late-GU toxicity are
\end{abstract}

This article is freely accessible online.

\footnotetext{
*These Authors contributed equally to this study.

Correspondence to: Giambattista Siepe, Radiation Oncology Center, Department of Experimental, Diagnostic and Specialty Medicine DIMES, University of Bologna, S. Orsola-Malpighi Hospital, via Massarenti 9, 40138 Bologna, Italy. Tel: +39 0512143564, e-mail: giambattista.siepe@gmail.com
}

Key Words: Hypofractionation, postoperative, prostate cancer, radiotherapy, review. conflicting. Further prospective studies are needed before including postoperative HFRT in clinical practice.

Prostate cancer $(\mathrm{PCa})$ is the most common non-skin cancer in males older than 70 years in Europe (1). Radical prostatectomy (RP) is a treatment option in patients with life expectancy longer than 10 years and organ-confined disease (1-2). Patients with adverse pathological features show 50-75\% 5-year biochemical failure rates after RP (3). Negative prognostic factors are extracapsular extension, seminal vesicles invasion, positive surgical margins, higher Gleason score and higher preoperative prostate-specific antigen (PSA) (4).

The efficacy of postoperative radiotherapy (RT) was demonstrated by three randomized clinical trials: Southwest Oncology Group (SWOG) 8794 (5), European Organisation for Research and Treatment of Cancer (EORTC) 22911 (6), and German Cancer Society (ARO) 96-02 (7). These studies showed that adjuvant RT significantly improves 10-year biochemical recurrence-free survival (bRFS), local control (LC) and disease-free survival (DFS).

Available literature data do not define the optimal dose and fractionation for adjuvant and salvage RT. The three randomized trials mentioned above used a lower total dose (60-64 Gy with conventional fractionation) compared to other retrospective and prospective non-randomized studies (8-10).

Radiobiological analyses suggest that $\mathrm{PCa} \alpha / \beta$ ratio is approximately 1.5 and thus lower compared to bladder and rectum (11). Therefore, the choice to prescribe a 
Table I. Patients characteristics.

\begin{tabular}{|c|c|c|c|c|c|c|c|c|c|}
\hline Reference, year & Institution & $\begin{array}{l}\text { Study } \\
\text { design }\end{array}$ & $\begin{array}{l}\mathrm{N}^{\circ} \\
\text { pts }\end{array}$ & $\begin{array}{c}\% \\
\text { setting }\end{array}$ & $\begin{array}{l}\text { Median } \\
\text { follow-up, } \\
\text { months } \\
\text { (range) }\end{array}$ & $\begin{array}{l}\text { GS } \\
\geq 7, \\
\%\end{array}$ & $\begin{array}{c}\text { Positive } \\
\text { surgical } \\
\text { margin, } \\
\%\end{array}$ & $\begin{array}{c}\text { Median PSA } \\
\text { at diagnosis, } \\
\text { ng/ml } \\
\text { (range) }\end{array}$ & $\begin{array}{c}\text { Median PSA } \\
\text { before RT, } \\
\text { ng/ml } \\
\text { (range) }\end{array}$ \\
\hline Syndikus I et al. 1996 (19) & $\begin{array}{l}\text { British Columbia; } \\
\text { Canada }\end{array}$ & $\begin{array}{l}\text { Prospective } \\
\text { Phase } 2\end{array}$ & 115 & $\begin{array}{l}\text { adj: } 77.4 \\
\text { salv: } 22.6\end{array}$ & $\begin{array}{l}\text { adj: } 87(59-121) \\
\text { salv: } 111(46-146)\end{array}$ & NR & 85.0 & $12(2-70) *$ & $2(0.1-21) *$ \\
\hline Lee LW et al. 2004 (20) & Manchester; UK & Retrospective & 37 & salv: 100 & $36(20-85)$ & 30.0 & 73.0 & $11.2(5.6-60)$ & $2.9(0.5-11.4)$ \\
\hline Cozzarini C et al. 2007 (21) & Milan; Italy & $\begin{array}{l}\text { Prospective } \\
\text { Phase } 1-2\end{array}$ & 23 & $\begin{array}{l}\text { adj: } 78.3 \\
\text { salv: } 21.7\end{array}$ & $11.5(3.4-25.7)$ & NR & NR & NR & NR \\
\hline Cozzarini C et al. 2008 (22) & Milan; Italy & $\begin{array}{l}\text { Prospective } \\
\text { Phase 1-2 }\end{array}$ & 50 & adj:100 & $25(15.5-31.6)$ & NR & 54.0 & 6.9 & 0.02 \\
\hline Wong G et al. 2008 (23) & Madison; USA & Retrospective & 50 & salv: 100 & $18.9(5.3-35.9)$ & 58.0 & 70.0 & $6.6(3-21.1)$ & $0.5(0.2-9.5)$ \\
\hline Alongi F et al. 2009 (24) & Milan; Italy & Retrospective & 43 & NE & NR & $\mathrm{NE}$ & NR & NE & NE \\
\hline Kruser TJ et al. 2011 (25) & Madison; USA & Retrospective & 108 & salv: 100 & $32.4(5.8-70.5)$ & $64.0^{\dagger}$ & $69.0^{\ddagger}$ & $6.79(2.2-38.5)^{\S}$ & $0.44(0.05-9.5)$ \\
\hline $\begin{array}{l}\text { Koukourakis M } \\
\text { et al. } 2012(26)\end{array}$ & $\begin{array}{l}\text { Alexandroupolis; } \\
\text { Greece }\end{array}$ & $\begin{array}{l}\text { Prospective } \\
\text { Phase 1-2 }\end{array}$ & 48 & $\begin{array}{l}\text { adj: } 43.8 \\
\text { salv: } 56.2\end{array}$ & $41(12-84)$ & 54.2 & 20.8 & NR & $\begin{array}{c}\text { adj: } 0.18^{\|} \\
(0.03-1.6) \\
\text { salv: } 2.2^{\|}(0-31)\end{array}$ \\
\hline Alongi F et al. 2013 (27) & $\begin{array}{l}\text { Milan; Italy and } \\
\text { Bellin zona, } \\
\text { Switzerland }\end{array}$ & Retrospective & 39 & $\begin{array}{l}\text { adj: } 76.9 \\
\text { salv: } 23.1\end{array}$ & $22.8(9-28)$ & NE & NR & NR & $0.32(0.01-3.25)$ \\
\hline Ippolito E et al. 2013 (28) & $\begin{array}{l}\text { Campobasso \& } \\
\text { Rome; Italy }\end{array}$ & $\begin{array}{l}\text { Prospective } \\
\text { Phase } 1\end{array}$ & 25 & adj: 100 & $19(6-36)$ & 76.0 & 72.0 & $12.45(3.80-54.0)$ & $\begin{array}{c}0.10 \\
(0.00-0.13)\end{array}$ \\
\hline $\begin{array}{l}\text { Massaccesi M et al. } \\
2013 \text { (29) }\end{array}$ & $\begin{array}{c}\text { Campobasso \& } \\
\text { Rome; Italy }\end{array}$ & $\begin{array}{c}\text { Prospective } \\
\text { Phase } 2\end{array}$ & 49 & $\begin{array}{l}\text { adj: } 79.6 \\
\text { salv: } 20.4\end{array}$ & NR & $55.8^{\mathrm{J}}$ & 57.1 & $10.2 * *$ & $\begin{array}{c}\text { adj: } 0.27^{\|} \\
\text {salv: } 1.25^{\|}\end{array}$ \\
\hline Cozzarini C et al. 2014 (30) & Milan; Italy & Retrospective & 247 & $\begin{array}{l}\text { adj: } 67.6 \\
\text { salv: } 32.4\end{array}$ & $68(54-81)$ & 34.4 & 57.0 & $8(5.6-12.7)$ & $\begin{array}{c}0.03 \\
(0.01-0.06)^{\dagger \dagger}\end{array}$ \\
\hline Katayama S et al. 2014 (31) & $\begin{array}{l}\text { Heidelberg, } \\
\text { Germany }\end{array}$ & $\begin{array}{l}\text { Prospective } \\
\text { Phase } 2\end{array}$ & 39 & $\begin{array}{l}\text { adj: } 28.2 \\
\text { salv: } 71.8\end{array}$ & NR & NR & NR & NR & $0.24(0.02-2.18)$ \\
\hline Gladwish A et al. 2015 (32) & Toronto; Canada & $\begin{array}{l}\text { Prospective } \\
\text { Phase 1-2 }\end{array}$ & 30 & $\begin{array}{l}\text { adj: } 13.3 \\
\text { salv: } 86.7\end{array}$ & $24(18-42)$ & 93.0 & 67.0 & NR & $0.12(0.01-1.42)$ \\
\hline Lewis S.L et al. 2016 (33) & $\begin{array}{l}\text { North Carolina; } \\
\text { USA }\end{array}$ & $\begin{array}{l}\text { Prospective } \\
\text { Phase } 2\end{array}$ & 56 & $\begin{array}{l}\text { adj: } 23.2 \\
\text { salv: } 76.8\end{array}$ & $48(21-67)$ & 85.0 & 76.0 & $8.5(3.7-154.8)$ & $1.14(0.01-40.3)$ \\
\hline Fersino S et al. 2017 (34) & $\begin{array}{l}\text { Negrar-Verona; } \\
\text { Italy }\end{array}$ & Retrospective & 125 & $\begin{array}{l}\text { adj: } 51.2 \\
\text { salv: } 48.8\end{array}$ & $18(6-53)$ & NR & 46.4 & NR & $\begin{array}{l}\text { adj: } 0.035 \\
\quad(0-0.2) \\
\text { salv } 0.45 \\
(0.2-5.1)\end{array}$ \\
\hline Macchia G et al. 2017 (35) & $\begin{array}{l}\text { Campobasso; } \\
\text { Italy }\end{array}$ & $\begin{array}{l}\text { Prospective } \\
\text { Phase } 1-2\end{array}$ & 124 & $\begin{array}{l}\text { adj: } 85.5 \\
\text { salv: } 14.5\end{array}$ & $30(13-92)$ & 78.2 & 84.7 & $7.6(0.1-80.8)$ & NR \\
\hline
\end{tabular}

Adj: Adjuvant; GS: Gleason score; NE: not evaluable; NR: not reported; pts: patients; salv: salvage; *setting adjuvant; †only 106 pts; ${ }^{\circ}$ only 105 pts; §only 103 pts; "mean; IGS > 7; **setting adjuvant; † interquartile range.

hypofractionated radiotherapy (HFRT) seems justified. Results from randomized and non-randomized trials evaluating feasibility and safety of this therapeutic approach are available for radical HFRT in non-resected PCa (12-14), but only few non-randomized studies have been published and no systematic review or meta-analyses are available about postoperative HFRT.

Therefore, the purpose of this systematic review is to analyse acute and late treatment-related sequelae of postoperative HFRT in PCa patients. Secondary endpoints of this trial are LC, overall survival (OS), and bRFS.

\section{Materials and Methods}

\section{Inclusion criteria}

Type of studies. In this review all clinical studies reporting toxicity in patients treated with postoperative HFRT were included, excluding case reports and reviews. Only studies published in English were included.

Type of participants. Only trials enrolling patients with resected non-metastatic PCa were included in this analysis (Table I).

Type of interventions. Eligible intervention included postoperative hypofractionated external beam RT independently by technique, 
Table II. Treatment characteristics.

\begin{tabular}{|c|c|c|c|c|c|c|c|}
\hline Reference, year & Technique & $\begin{array}{l}\text { Dose, Gy } \\
\text { (median) }\end{array}$ & $\begin{array}{l}\text { Dose per } \\
\text { fraction, Gy } \\
\text { (median) }\end{array}$ & $\begin{array}{l}\text { Image } \\
\text { guidance }\end{array}$ & $\begin{array}{c}\text { EQD2 } \\
(\alpha / \beta=1.5)^{*}\end{array}$ & $\begin{array}{c}\mathrm{EQD} 2 \\
(\alpha / \beta=3)^{*}\end{array}$ & $\begin{array}{l}\text { Patients } \\
\text { receiving } \\
\text { HT, \% }\end{array}$ \\
\hline Syndikus I et al. 1996 (19) & NR & PB: $50.0-55.0\left(52^{\dagger}\right)$ & PB: $2.0-3.1\left(2.76^{\dagger}\right)$ & NR & 63.3 & 59.9 & 15.6 \\
\hline Lee LW et al. 2004 (20) & 3DCRT & PB: $50.0-52.5(50)$ & PB: $2.5-2.6(2.5)$ & NR & $57.1-61.5$ & $55.0-58.8$ & NR \\
\hline Cozzarini C et al. 2007 (21) & IMRT-SIB-HTT & $\begin{array}{l}\text { PB: } 64.4-72.0(72.0) \\
\text { PNI: } 50.4-54.0(52.0)\end{array}$ & $\begin{array}{l}\text { PB: } 2.2-2.6 \\
\text { PNI: } 1.5-1.9\end{array}$ & MVCT & $68.1-84.3$ & $66.9-80.6$ & NR \\
\hline Cozzarini C et al. 2008 (22) & IMRT & PB: 58.0 & PB: 2.9 & MVCT & 73.0 & 68.0 & NR \\
\hline Wong GW et al. 2008 (23) & IMRT & $\begin{array}{l}\text { PB: } 65.0-70.0 \\
\text { PNI: } 54.0-56.0^{\ddagger}\end{array}$ & $\begin{array}{l}\text { PB: } 2.5 \\
\text { PNI: } 2.0\end{array}$ & MVCT; U/S & $74.3-80.0$ & $71.5-77.0$ & 8.0 \\
\hline Alongi F et al. 2009 (24) & IMRT & $\begin{array}{c}\text { PB: } 64.4-70.0 \\
\text { PNI: } 50.4-54.0(51.8)\end{array}$ & $\begin{array}{l}\text { PB: } 2-2.6(2.35) \\
\text { PNI: } 1.8-2(1.85)\end{array}$ & NR & $68.1-82.0$ & $67.0-78.4$ & NE \\
\hline Kruser TJ et al. 2011 (25) & IMRT & $\begin{array}{c}\text { PB: } 65.0-70.0 \\
\text { PNI: } 52.0-56.0^{\S}\end{array}$ & $\begin{array}{l}\text { PB: } 2.5 \\
\text { PNI: } 2.0\end{array}$ & MVCT; U/S & $74.3-80.0$ & $71.5-77.0$ & 17.0 \\
\hline Koukourakis M et al. 2012 (26) & 3DCRT ${ }^{\| \prime}$ & $\begin{array}{l}\text { PB: } 51.0 \\
\text { PNI: } 37.8\end{array}$ & $\begin{array}{l}\text { PB: } 3.4 \\
\text { PNI: } 2.7\end{array}$ & NR & 71.4 & 65.3 & 47.9 \\
\hline Alongi F et al. 2013 (27) & VMAT & PB: 70.0-71.4 (70) & PB:2.5-2.55 & $\mathrm{CB}-\mathrm{CT}$ & $80.0-82.6$ & $77.0-79.2$ & NR \\
\hline Ippolito E et al. 2013 (28) & IMRT-SIB & $\begin{array}{c}\text { PB: } 56.75,59.75 \\
61.25,62.5^{5} \\
\text { PNI: } 45.0\end{array}$ & $\begin{array}{c}\text { PB: } 2.27,2.39, \\
2.45,2.50 \\
\text { PNI: } 1.8\end{array}$ & NR & $\begin{array}{c}61.1-66.4- \\
69.1-71.4\end{array}$ & $\begin{array}{c}59.8-64.4- \\
66.7-68.7\end{array}$ & NR \\
\hline Massaccesi M et al. 2013 (29) & IMRT-SIB & $\begin{array}{c}\text { PB: } 62.5 \\
\text { PNI: } 45.0\end{array}$ & $\begin{array}{l}\text { PB: } 2.5 \\
\text { PNI: } 1.8\end{array}$ & NR & 71.4 & 68.75 & 73.4 \\
\hline Cozzarini C et al. 2014 (30) & IMRT-SIB & $\begin{array}{c}\text { PB: } 58.0-72.8(71.4) \\
\text { PNI: } 50.0-52.0\end{array}$ & $\begin{array}{c}\text { PB: } 2.35-2.90(2.50) \\
\text { PNI: }(1.8)\end{array}$ & IGRT & $72.4-72.9$ & $70.4-68.4$ & 54.0 \\
\hline Katayama S et al. 2014 (31) & IMRT & PB: 54.0 & PB: 3.0 & MVCT & 69.4 & 64.8 & 12.8 \\
\hline Gladwish A et al. 2015 (32) & IMRT & PB: 51.0 & PB: 3.0 & IGRT & 65.6 & 61.2 & 13.0 \\
\hline Lewis SL et al. 2016 (33) & IMRT & PB: $57.5-65.0(65.0)$ & PB: 2.5 & IGRT & $65.7-74.3$ & $63.2-71.5$ & 17.8 \\
\hline Fersino S et al. 2017 (34) & VMAT & $\begin{array}{l}\text { PB: } 65.5-71.4(66.0) \\
\text { PNI: } 50.4-54.0(52.5)\end{array}$ & $\begin{array}{l}\text { PB: } 2.2-2.4 \\
\text { PNI: } 1.8-2.0\end{array}$ & $\mathrm{CB}-\mathrm{CT}$ & $69.2-79.6$ & $68.1-77.1$ & NR \\
\hline Macchia G et al. 2017 (35) & IMRT-SIB & $\begin{array}{l}\text { PB: } 62.5 \\
\text { PNI: } 45.0\end{array}$ & $\begin{array}{l}\text { PB: } 2.5 \\
\text { PNI: } 1.8\end{array}$ & NR & 71.4 & 68.7 & 79.8 \\
\hline
\end{tabular}

3DCRT: 3D Conformal Radiotherapy; adj: adjuvant; CB-CT: cone beam CT; conc: concomitant; EQD2: equivalent dose in 2 Gy fractions; GS: Gleason score; HT: hormone therapy; HTT: Helical Tomotherapy; IGRT: image guided radiotherapy; IMRT: intensity modulated radiation therapy; MVCT: Megavoltage CT; neoadj : neoadjuvant; NE: not evaluable; NR: not reported; PB: prostate bed; pts: patients; PNI: prophylactic nodal irradiation; SIB: simultaneous Integrated Boost; VMAT: Volumetric Modulated Arc Therapy. *prostate bed dose; †mean; $\ddagger_{\text {only }} 4$ pts; $\S_{\text {only }}$ in 14 pts; "amifostine cytoprotection in association; Idose escalation.

total dose and treatment intent (adjuvant or salvage) after RP with or without lymphadenectomy. Additional treatments (neoadjuvant and/or concurrent and/or adjuvant hormone therapy) and supportive care were not exclusion criteria (Table II).

Type of outcome measures. Primary endpoint of the analysis was treatment-related toxicity after HFRT in postoperative setting and secondary endpoints were LC, OS, and bRFS (Table III).

Literature search strategy. Trials were independently selected by two different authors (GS and $\mathrm{MB}$ ) and a third author resolved potential discrepancies (AGM). The same two authors (GS and MB) extracted data independently with resolution of all differences by the third author (AGM). Based on the PRISMA methodology, a bibliographic search was performed using the PubMed database. The search algorithm was "prostate" (MeSH) AND "hypofractionated" (MeSH) AND "postoperative" (MeSH). There were no time limits in the literature search. We included only studies in English language and we excluded reviews, case reports and study protocols. Studies including radical RT, conventional fractionation or palliative treatments were also excluded in the review process.

\section{Results}

Characteristics of included studies. Through the literature research, performed as previously reported, 21 records were identified. Figure 1 shows the selection process of trials included in this review. Four papers were excluded: two were not pertinent $(15,16)$, one was a case report $(17)$, and the other was a study protocol (18). A total of 17 studies fulfilled all the inclusion criteria reporting data on 1208 patients. Among the selected trials, 12 were performed in European centers, 3 in USA, and 2 in Canada. Seven studies had a retrospective design, one was a phase 1 trial, four were phase 2 trials, and five were phase 1-2 trails. 
Table III. Results.

\begin{tabular}{|c|c|c|c|c|c|c|}
\hline $\begin{array}{l}\text { Reference, } \\
\text { year }\end{array}$ & $\begin{array}{l}\text { Acute toxicity G } \\
\geq 3, \% \text { (Scale) }\end{array}$ & $\begin{array}{l}\text { Late toxicity G } \\
\geq 2, \% *(\text { Scale })\end{array}$ & $\mathrm{LC}, \%$ & OS, $\%$ & bRFS, $\%$ & Main findings \\
\hline Syndikus I et al. 1996 (19) & NR & $\begin{array}{l}\text { GI: } 8.7 ; \text { GU:46.1 } \\
\text { (RTOG/EORTC) }\end{array}$ & $\begin{array}{l}5-\mathrm{y}: 69.0^{\dagger} \\
10-\mathrm{y}: 54.0^{\dagger}\end{array}$ & $10-\mathrm{y}: 91.0^{\ddagger}$ & NR & $\begin{array}{l}\text { early post-operative } \mathrm{RT} \\
<\text { local recurrence rates }\end{array}$ \\
\hline Lee LW et al. 2004 (20) & $\begin{array}{l}\text { GI: 0; GU: } 0 \\
\text { (RTOG) }\end{array}$ & $\begin{array}{l}\text { GI: } 3.0 ; \text { GU:0 } \\
\text { (RTOG/EORTC) }\end{array}$ & NR & $100 *$ & $\begin{array}{l}1-y: 92.0 \\
2-y: 83.0 \\
3-y: 74.0\end{array}$ & $\begin{array}{l}\text { Salv RT in PSA }<2 \mathrm{ng} / \mathrm{mL} \\
\text { improves biochemical control }\end{array}$ \\
\hline Cozzarini C et al. 2007 (21) & $\begin{array}{l}\text { GI: } 0 \text {; GU: } 0 \\
\text { (RTOG) }\end{array}$ & NR & NR & NR & NR & $\begin{array}{l}\text { Efficient sparing of intestinal cavity } \\
\text { with HTT compared to IMRT }\end{array}$ \\
\hline Cozzarini C. et al. 2008 (22) & $\begin{array}{l}\text { GI: 0; GU: } 2.0 \\
\quad \text { (RTOG) }\end{array}$ & $\begin{array}{l}\text { GI: } 0 ; \text { GU: } 12.0 \\
\text { (RTOG/EORTC) }\end{array}$ & NR & NR & $100^{*}$ & $\begin{array}{c}\text { Acute toxicity and late toxicity } \\
\text { outcomes, excellent with HTT post RP }\end{array}$ \\
\hline Wong GW et al. 2008 (23) & $\begin{array}{l}\text { GI: 0; GU: } 0 \\
\text { (RTOG) }\end{array}$ & $\begin{array}{l}\text { GI: } 4.0 ; \mathrm{GU}: 4.0 \\
\text { (RTOG/EORTC) }\end{array}$ & NR & $98.0 *$ & $\begin{array}{l}1-y: 83.7 \\
2-y: 72.9\end{array}$ & $\begin{array}{l}\text { Biochemical control rates significantly } \\
\text { improved in pts with PSA level }<0.4\end{array}$ \\
\hline Alongi F et al. 2009 (24) & $\begin{array}{l}\text { GI:0; GU:0 } \\
\text { (RTOG) }\end{array}$ & NR & NR & NR & NR & $\begin{array}{l}\text { Excellent profile of acute toxicity in } \\
\text { WPRT in adju/salv post-operative } \geq 70 \mathrm{~Gy}\end{array}$ \\
\hline Kruser TJ et al. 2011 (25) & $\begin{array}{l}\text { GI: 0; GU: } 1.0 \\
\text { (RTOG) }\end{array}$ & $\begin{array}{l}\text { GI: } 4.0 ; \text { GU: } 15.0 \\
\text { (RTOG/EORTC) }^{\S}\end{array}$ & NR & $99.1 *$ & $4-y: 67.0$ & $\begin{array}{l}\text { Reduced treatment time; } \\
\text { low rates of toxicity }\end{array}$ \\
\hline $\begin{array}{l}\text { Koukourakis M et al. } \\
2012 \text { (26) }\end{array}$ & $\begin{array}{l}\text { GI: 0; GU: } 0 \\
\text { (CTCAE) }\end{array}$ & $\begin{array}{c}\text { GI: } 0 ; \text { GU: } 0 \\
\text { (CTCAE/EORTC) }\end{array}$ & $93.7 *$ & NR & $85.4 *$ & $\begin{array}{l}\text { Better pts outcome with high dose } \\
\text { of amifostine ( } 1000 \mathrm{mg}) \text {; low } \\
\text { incidence of late radiation events }\end{array}$ \\
\hline Alongi F et al. 2013 (27) & $\begin{array}{l}\text { GI: } 0 \text {; GU: } 0 \\
\text { (RTOG) }\end{array}$ & $\begin{array}{l}\text { GI: } 0 ; \text { GU: } 11.0 \\
\text { (RTOG/EORTC) }\end{array}$ & NR & NR & NR & $\begin{array}{l}\text { Better late rectal toxicity profile with } \\
\text { VMAT; good bladder and rectum sparing }\end{array}$ \\
\hline Ippolito E et al. 2013 (28) & $\begin{array}{l}\text { GI: 0; GU: } 0 \\
\text { (RTOG) }\end{array}$ & NR & NR & NR & NR & $\begin{array}{c}\text { Total dose of } 62.5(2.5) \mathrm{Gy} \text { is feasible } \\
\text { in terms of acute toxicity and overall } \\
\text { treatment time reduction }\end{array}$ \\
\hline Massaccesi M et al. 2013 (29) & $\begin{array}{l}\text { GI: 0; GU: } 1.9 \\
\text { (RTOG) }\end{array}$ & NR & NR & NR & NR & $\begin{array}{l}62.5(2.5) \text { Gy compares favourably } \\
\text { with that of 3DCRT high doses }\end{array}$ \\
\hline Cozzarini C et al. 2014 (30) & NR & $\begin{array}{l}\text { GI: NR; GU: } \\
\text { 16.5**; 5-y: } 18.1 \\
\text { (CTCAE } 4.0 \text { ) }\end{array}$ & NR & NR & NR & $\begin{array}{c}\text { The toxicity increased when the median } \\
\text { dose per fraction was increased from } \\
1.8 \text { Gy to } 2.35 \text { to } 2.55\end{array}$ \\
\hline Katayama S et al. 2014 (31) & $\begin{array}{l}\text { GI: } 0 ; \mathrm{GU}: 0 \\
\text { (CTCAE } 4.0 \text { ) }\end{array}$ & $\mathrm{NR}$ & NR & NR & NR & $\begin{array}{l}\text { Hyp IMRT of PB is well tolerated } \\
\text { with severe acute side effects }\end{array}$ \\
\hline Gladwish A et al. 2015 (32) & $\begin{array}{l}\text { GI: 0; GU: } 3.0 \\
\text { (CTCAE 3.0) }\end{array}$ & $\begin{array}{l}\text { GI: } 6.0 ; \mathrm{GU}: 3.0 \\
\text { (CTCAE 3.0) }\end{array}$ & NR & NR & $83.0 *$ & $\begin{array}{l}\text { Well tolerate hyp in terms } \\
\text { of toxicity and QoL }\end{array}$ \\
\hline Lewis SL et al. 2016 (33) & $\begin{array}{l}\text { GI: 0; GU: } 0 \\
\text { (CTCAE 4.0) }\end{array}$ & $\begin{array}{l}\text { GI: } 3.6 ; \mathrm{GU}: 66.1 \neq \\
\text { (CTCAE 4.0) }\end{array}$ & NR & $96.4 *$ & $4-y: 75.0$ & $\begin{array}{l}\text { Late grade } 3 \mathrm{GU} \text { toxicity was higher } \\
\text { than anticipated with hyp of } 65 \mathrm{~Gy}\end{array}$ \\
\hline Fersino S et al. 2017 (34) & $\begin{array}{l}\text { GI: } 0 ; \text { GU: } 0.8 \\
\text { (CTCAE } 4.0)\end{array}$ & $\begin{array}{l}\text { GI: } 8 ; \text { GU: } 12.0^{\ddagger \neq} \\
\quad \text { (CTCAE } 4.0)\end{array}$ & NR & NR & $\begin{array}{l}\text {-y: } 94.0(\mathrm{adj}) \\
\text {-y: } 77.0(\text { salv })\end{array}$ & $\begin{array}{l}\text { j) Moderate hypofractionated } \\
\text { postoperative RT with } \\
\text { v) } \\
\text { VMAT was feasible and safe }\end{array}$ \\
\hline Macchia G et al. 2017 (35) & $\begin{array}{l}\text { GI: 0; GU: } 0.8 \\
\text { (RTOG) }\end{array}$ & $\begin{array}{c}\text { 5-y GI: } 1.1 \\
\text { 5-y GU: } 7.3 \\
\text { (RTOG/EORTC) }\end{array}$ & $\begin{array}{l}3-y: 99.9 \\
5-y: 94.9\end{array}$ & $\begin{array}{l}3-y: 100 \\
5-y: 100\end{array}$ & $\begin{array}{l}3-y: 91.1 \\
5-y: 86.5\end{array}$ & $\begin{array}{l}\text { Hyp IMRT-SIB provides excellent } \\
\text { Long-term bRFS with minimal } \\
\text { rate of late complications } \\
\text { when combined with HT; }\end{array}$ \\
\hline
\end{tabular}

ADJ: Adjuvant; bPFS: biochemical progression-free survival; bRFS: biochemical relapse free survival; CTCAE: Common Terminology Criteria for Adverse Events; DFS: disease-free survival; FU: follow-up; hyp: hypofractionated; IMRT: intensity modulated radiation therapy; GI: gastrointestinal; GU: genitourinary; HTT: Helical Tomotherapy; LC: local control; mo: months; NR: not reported; OS: overall survival; PB: prostate bed; pts: patients;

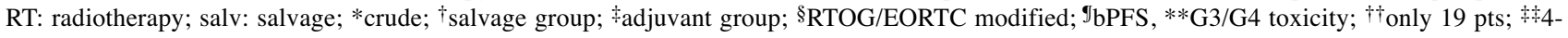
y grade 3 late toxicity was $28 \%$.

Literature review. The first report on postoperative HFRT for PCa was published in 1996. In this study Syndikus and colleagues enrolled a total of 203 patients: 88 were treated with RP alone, 89 underwent early postoperative RT, generally because of pT3 stage, and 26 received salvage RT for local recurrence (postoperative RT: 115 patients). The aim of the analysis was to evaluate the impact of RT using a total dose to the prostate bed of 50-55 Gy with 2.0-3.1 Gy daily fractions. Late toxicity was scored with the RTOG/EORTC scale. Five- and 10-year LC were $69.0 \%$ and $54.0 \%$ in patients treated for local recurrence, respectively. Actuarial 10-year OS for early postoperative RT group was 


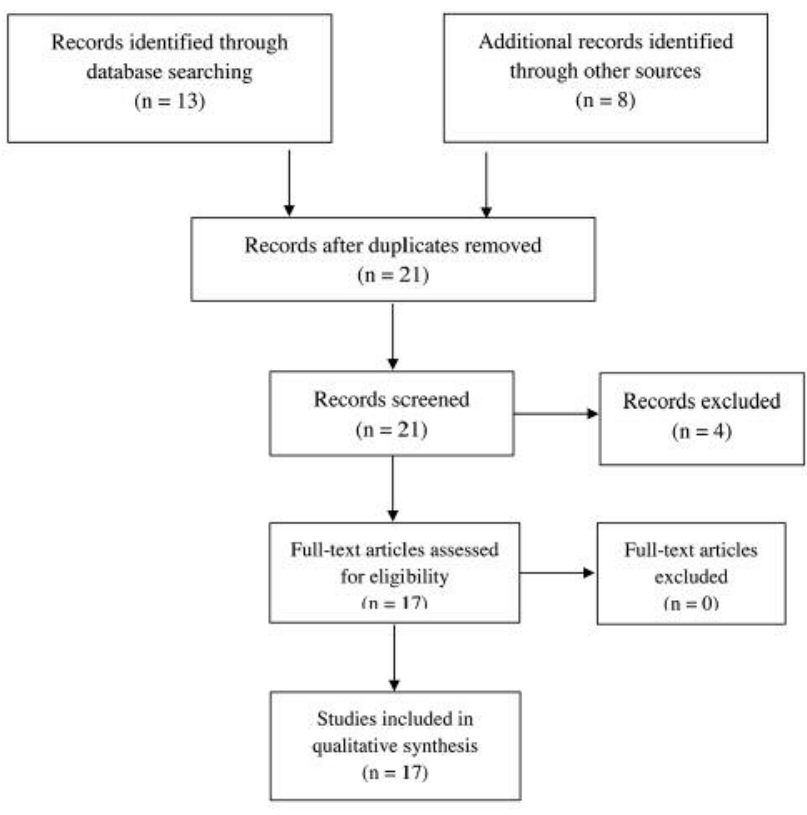

Figure 1. Flow diagram of study identification and selection.

$91.0 \%$. Grade $\geq 2$ late gastrointestinal (GI) and genitourinary (GU) toxicity rates in adjuvant setting were $10.0 \%$ and $44.0 \%$, respectively, and in salvage setting they were $4.0 \%$ and $54.0 \%$, respectively. Based on these results, the authors concluded that local RT in pT3 stage has a positive impact on LC but not on OS. Because of the high rate of severe late urinary complications, they suggested to treat in the adjuvant setting only patients with a high risk of local recurrence (19).

In their retrospective analysis, Lee and co-workers included 37 patients with biochemical relapse after RP. Patients underwent salvage HFRT using 50.0-52.2 Gy in 20 fractions (2.5-2.6 Gy daily fractions). Acute and late toxicity was evaluated with RTOG and RTOG/EORTC scales, respectively. No patients died due to $\mathrm{PCa}$ or developed distant metastases. One-, 2- and 3-year bRFS was $92.0 \%$, $83.0 \%$, and $74.0 \%$, respectively. No case of grade $\geq 3$ acute and late toxicity was reported. Only $3.0 \%$ grade $\geq 2$ late GI toxicity crude rate was recorded. The authors concluded that this RT regimen achieved prolonged biochemical control with good tolerance (20).

The first Italian phase 1-2 trial was published in 2007. Cozzarini and colleagues, using helical tomotherapy based postoperative HFRT, reported acute toxicity in 23 patients (78.3\% and $21.7 \%$ treated with adjuvant and salvage intent, respectively). With a median dose of $74.2 \mathrm{~Gy}$ on surgical bed and moderately hypofractionated regimen, no patient developed grade $\geq 3$ acute toxicity according to the RTOG scale (21).
One year later, the same group published the results of a case series of 50 patients with high risk disease treated with adjuvant dose of 58.0 Gy in 2.9 Gy per fraction on prostatic fossa using helical tomotherapy. No grade $\geq 3$ acute and grade $\geq 2$ late GI toxicity was recorded, without differences compared to patients treated with three-dimensional conformal radiotherapy (3D-CRT) and a conventionally fractionated dose. Only $2.0 \%$ developed grade $\geq 3$ acute GU toxicity and $12.0 \%$ grade $\geq 2$ late GU toxicity according to the RTOG and RTOG/EORTC scale, respectively. In addition, bRFS was $100 \%$ with a median follow-up of 25 months (22).

Wong and his group reported the results of salvage HFRT in a retrospective analysis on 50 patients with biochemical relapse. On the surgical bed 2.5 Gy were delivered daily for 26-28 fraction (total dose $=65-70$ Gy). Based on RTOG and RTOG/EORTC scales, no grade $\geq 3$ acute GI and GU toxicity was reported and only $4.0 \%$ of patients showed grade $\geq 2$ late GI and GU toxicity. One- and 2-year bRFS was $83.7 \%$ and $72.9 \%$, respectively, with biochemical control rates significantly better in patients with PSA level $<0.4 \mathrm{ng} / \mathrm{ml}(p=0.018)(23)$.

Alongi and co-workers used IMRT-based postoperative RT in 43 patients with a total dose of 64.4-70.0 Gy (2.0-2.6 Gy) on the prostate surgical bed and 50.4-54.0 Gy (1.8-2.0 Gy) to the pelvis. Despite the use of whole-pelvic irradiation, no patient showed any grade $\geq 3$ acute toxicity according to the RTOG scale (24).

Kruser and colleagues published their experience on HFRT (65-70 Gy in 2.5 Gy fractions in about 5 weeks) in 108 patients with post-prostatectomy biochemical recurrence. GI and GU grade $\geq 3$ acute toxicity rates were $0 \%$ and $1.0 \%$, respectively. GI and GU late toxicity were $4.0 \%$ and $15.0 \%$, respectively. Four-year bRFS was $67.0 \%$ and only one patient died from hormonal refractory $\mathrm{PCa}$ with a median follow up of 32.4 months. The authors concluded that salvage HFRT is safe and effective (25).

The Greek group coordinated by Koukourakis enrolled 48 patients with high-risk disease or recurrent PCa. HFRT was delivered on prostatic bed (51.0 Gy in 3.4 Gy per fraction) and pelvic nodes (37.8 Gy in 2.7 Gy per fraction) with amifostine cytoprotection. With a median follow up of 41.0 months, no GI and GU toxicity was reported and $14.6 \%$ of patients showed PSA biochemical failure with $6.3 \%$ local relapse rate. Based on the low toxicity rate the authors considered this treatment as feasible (26).

Alongi and co-workers published in 2013 the results of post-operative HFRT (adjuvant/salvage) delivered with Volumetric Modulated Arc Therapy (VMAT). Thirty-nine patients were enrolled, $76.9 \%$ and $23.1 \%$ for adjuvant and salvage RT, respectively. They were treated with $70.0 \mathrm{~Gy}$ median dose to the prostatic bed (2.5-2.55 Gy per fraction). Based on RTOG-EORTC scale, $11.0 \%$ of patients showed grade $\geq 2$ late $\mathrm{GU}$ toxicity with a median follow up of 22.8 
months. The authors observed a lower rate of late rectal toxicity with VMAT technique (27).

In the same year two other Italian studies were published. Ippolito and colleagues enrolled 25 patients undergoing adjuvant RT for high risk PCa in a phase 1 trial on postoperative Intensity Modulated Radiation Therapy with simultaneous integrated boost (IMRT-SIB). A dose-escalation (4 levels) was performed only on the surgical bed. The recommended dose was 62.5 Gy in 2.5 Gy per fraction based on the low acute toxicity rate ( $0 \%$ grade $\geq 3$ acute GI and GU toxicity, RTOG scale) (28).

Massaccesi and co-workers enrolled 49 patients after RP in a phase 2 trial. From this cohort of patients, $79.6 \%$ and $20.4 \%$ were treated with adjuvant and salvage intent, respectively. IMRT-SIB was prescribed to the whole pelvis (45 Gy in $1.8 \mathrm{~Gy}$ per fraction) and to the prostatic bed (62.5 Gy in 2.5 Gy per fraction). Only $1.9 \%$ of patients showed grade $\geq 3$ acute GU toxicity according to RTOG criteria. No cases of grade $\geq 3$ acute GI toxicity were recorded. The authors concluded that hypofractionated IMRT-SIB reduces the overall treatment time and shows an acute toxicity profile which compares favourably with 3D-CRT (29).

Cozzarini and colleagues reported late toxicity rates from a group of 247 patients $(67.6 \%$ and $32.4 \%$ treated with adjuvant and salvage intent, respectively) undergoing HFRT (median dose: $71.4 \mathrm{~Gy}$; median dose per fraction: $2.5 \mathrm{~Gy}$ ). Five-year grade 3-4 late GU toxicity was recorded in $18.1 \%$ of patients (CTCAE 4.0). The toxicity rate progressively worsened with the dose per fraction increasing from $1.8 \mathrm{~Gy}$ to $2.55 \mathrm{~Gy}$. The authors observed that this risk of urinary effects must be considered in the benefit-risk ratio (30).

Katayama and co-workers in the PRIAMOS- 1 phase 2 trial evaluated the safety and toxicity of hypofractionated IMRT on the prostate bed (54 Gy in $3 \mathrm{~Gy}$ per fraction). No patient developed grade $\geq 3$ acute GI and/or GU toxicity based on CTCAE 4.0 (31).

Gladwish and colleagues tested adjuvant and salvage HFRT in a prospective phase 1-2 study. Thirty men treated with $51.0 \mathrm{~Gy}$ in $3 \mathrm{~Gy}$ per fraction showed $0 \%$ and $3.0 \%$ grade $\geq 3$ acute GI and GU toxicity, respectively. Grade $\geq 2$ late GI and GU adverse effects were reported in $3.0 \%$ and $6.0 \%$ of patients, respectively, based on CTCAE 3.0 criteria. Crude rate of bRFS was recorded in $83.0 \%$ of patients. The authors concluded that treatment tolerance and biochemical control of the disease were encouraging (32).

In Lewis and colleagues trial, 56 IMRT hypofractionated adjuvant or salvage treatments were performed delivering 57.5-65.0 Gy in 2.5 Gy per fraction on the prostate bed. With a median follow up of 48 months, grade $\geq 2$ late GI and GU toxicity rates were $3.6 \%$ and $66.1 \%$, respectively, based on CTCAE 4.0. No cases of grade $\geq 3$ acute GI and GU toxicity. Crude OS was $96.4 \%$ and actuarial 4-year bRFS was $75.0 \%$ (33).
Fersino and co-workers trial (34) retrospectively analyzed 125 patients previously treated with moderate adjuvant or salvage HFRT. Based on CTCAE 4.0, grade $\geq 3$ acute GI and GU toxicity rates were $0 \%$ and $0.8 \%$, respectively. Grade $\geq$ 2 late GI and GU were observed in $8.0 \%$ and $12.0 \%$, respectively. Actuarial 3-year bRFS in adjuvant and salvage setting was $94.0 \%$ and $77.0 \%$, respectively.

The last published study on postoperative HFRT was the Macchia and collegues trail (35). This Italian group in a prospective phase 1-2 study enrolled 124 patients: $85.5 \%$ and $14.5 \%$ for adjuvant and salvage RT, respectively. Using IMRTSIB (62.5 Gy and 45 Gy in 25 fractions to the prostate bed and pelvic nodes) grade $\geq 3$ acute GI and GU toxicity was reported in $0 \%$ and $0.8 \%$ of patients, respectively. Five-year grade $\geq 2$ late GI and GU was $1.1 \%$ and $7.3 \%$ based on RTOG/EORTC scale. Three- and 5-year LC, OS, and bRFS were $99.9 \%$ and $94.9 \%, 100 \%$ and $100 \%$, and $91.1 \%$ and $86.5 \%$, respectively.

Literature analysis. Seventeen eligible studies were included. (19-35) These retrospective $(20,23-25,27,30,34)$ [7] and prospective $(19,21,22,26,28,29,31-33,35)$ [10] trials had heterogeneous characteristics in terms of dose, target definition and combination with hormonal therapy. Median follow-up ranged between 11.5 and 111.0 months (median: 30.0 months).

Patients characteristics. A total of 1208 patients were included. Patients treated for adjuvant and salvage setting in the different studies ranged between $13.3 \%$ and $100 \%$ (median: $76.9 \%$ ), and between $14.5 \%$ and $100 \%$ (median: $52.5 \%$ ), respectively. One trial did not report the specific percentage of patients treated with adjuvant and salvage HFRT (24). Gleason grading was reported in ten trials (20, $23,25,26,28-30,32,33,35)$. Range and median of pathological Gleason score $\geq 7$ were $30.0-93.0 \%$ and $61.0 \%$, respectively. Thirteen authors $(19,20,22,23,25,26,28-30$, 32-35) reported data on positive surgical margins with a median value of $69.0 \%$ (range $=21.0-85.0 \%$ ). PSA at diagnosis and before RT, were reported in ten $(19,20,22$, $23,25,28-30,33,35)$ and fourteen $(19,20,22,23,25-34)$ trials (median: $8.25 \mathrm{ng} / \mathrm{ml}$ and $0.32 \mathrm{ng} / \mathrm{ml}$, respectively).

Treatment characteristics. In all trials, the RT technique was specified except in one (19). Most (12 trials) were performed with IMRT $(21-25,28-33,35)$ and 5 of these used an IMRTSIB approach $(21,28-30,35)$. VMAT technique was used in two series $(27,34)$ and 3DCRT in two trials $(20,26)$.

Clinical targets volumes definitions were: prostate bed alone in 7 studies $(19,20,22,27,31-33)$ and prostate bed and pelvic lymph nodes in $10(21,23-26,28-30,34,35)$ trials. The delivered dose to prostate bed and pelvic nodes was 50.074.2 Gy and 37.8-56.0 Gy, respectively. Fractionation ranged between 2.0 and $3.4 \mathrm{~Gy}$ and between 1.8 and $2.7 \mathrm{~Gy}$ for prostate bed and pelvic nodes, respectively. 
Some form of image guidance was used in 10 trials (21$23,25,27,30-34)$ while in 6 reports $(19,20,24,26,28,29$, $35)$ this information was not available.

EQD2 calculated with $\alpha / \beta=1.5$ and $\alpha / \beta=3$ ranged between 57.1 and 82.6 Gy and between 55 and $79.2 \mathrm{~Gy}$, respectively, with this value not evaluable in 1 trial (21).

Data on androgen deprivation therapy were reported in 10 series $(19,23,25,26,29-33,35)$ with $17.4 \%$ median percentage of patients receiving this systemic treatment (range $=8.0-79.8 \%)$.

\section{Results}

No case of Grade $\geq 3$ acute GI toxicity was recorded. Grade $\geq 3$ acute GU toxicity ranged between $0 \%$ and $3.0 \%$ (median: $0 \%$ ).

Crude rates of Grade $\geq 2$ late GI toxicity were $0-8.7 \%$ (median: $3.6 \%$ ) and crude rates of grade $\geq 2$ late GU toxicity were $0-66.0 \%$ (median: $12.0 \%$ ). Five-year grade $\geq 2$ late GU toxicity ranged between $7.3 \%$ and $18.1 \%$. LC was reported only in three studies: $93.7 \%$ (26) (crude rate), and $69.0 \%$ (19) and $94.9 \%$ (35) at 5-years, respectively. Crude rate of OS ranged between $96.4 \%$ and 100\% (median: 98.5\%). Actuarial rates of OS were $100 \%$ (35) at 3 and 5 years and $91.0 \%$ (19) at 10 years. Crude rate of bRFS was $83.0 \%$ (32), $85.4 \%$ (26), and $100 \%$ (22) in three studies, respectively. Actuarial rates of bRFS ranged between $83.7 \%$ and $92.0 \%$ at 1 year, $72.9 \%$ and $83.0 \%$ at 2 years, and $74.0 \%$ and $94.0 \%$ (median: $84.0 \%$ ), $67.0 \%$ and $75.0 \%, 86.5 \%$ at 3,4 and 5 years, respectively (data reported in 6 trails).

\section{Discussion}

$\mathrm{RP}$ is one of the standard treatment options for patients with localized PCa and life expectancy longer than 10 years, regardless of risk category $(1,2)$. However, up to $30 \%$ of patients treated with surgery require postoperative RT for high-risk pathological features or for biochemical failure (3538). $\mathrm{PCa}$ is a relatively radio-resistant tumor, with a strong dose-response relationship. In fact, there is evidence that biochemical control of disease improves by increasing the delivered RT dose. Prospective phase 1-2 trials have shown the efficacy and safety of postoperative treatment with total doses $\geq 70$ Gy and standard fractionation on surgical bed, with improved bRFS without significant worsening of toxicity $(10,39,40)$. Based on PCa low $\alpha / \beta$ ratio, several trials tested HFRT in a curative setting (12-14). However high-level evidence in the adjuvant and salvage setting are currently lacking.

This is the first systematic analysis comparing published trials on postoperative HFRT in patients with PCa, without time limits. In our analysis no randomized trials were found, and most studies (eleven out of seventeen) enrolled a small number of patients $(\leq 50)$ with a short follow-up duration.
Furthermore, the different studies were heterogeneous in terms of pathological features of disease, dose, radiotherapy aim, target volume and concomitant systemic therapy.

Within these limits, preliminary results on HFRT in this setting showed an acceptable disease control with reasonable radiotherapy-induced toxicity profile.

Comparing the seventeen selected trials there are different results about late radiation-induced effects (grade $\geq 2$ late $\mathrm{GU}$ toxicity: 0-66.1\%, median: $12.0 \%$ ).

Cozzarini and colleagues reported a high rate (5-year: $18.1 \%$ ) of grade $\geq 3$ late GU toxicity, significantly higher compared to a cohort of patients receiving conventionally fractionated RT (5-year: 6.9\%) (30). In multivariate analysis, acute grade $\geq 2$ and dose per fraction independently predicted late GU toxicity. The highest percentage of crude toxicity (grade $\geq 2$ late GU: $66.1 \%$ ) with a median follow-up of 48.0 months (range=21-67 months) was reported by Lewis's group (33). The reason of this unexpected outcome is unclear because the authors used an IG-IMRT technique delivering a similar total dose and dose per fraction compared to other studies (median dose: 65.0 Gy in 2.5 Gy per fraction). Even the low percentage of patients receiving hormone suppressive therapy (17.8\%) as well as RT target (prostatic fossa only) cannot explain this result. The authors of this analysis suggested some explanation in a subsequent publication (41). All their patients were treated and followed based on a detailed electronic medical record system. This could have given the opportunity to capture intermittent events normally not detected with a standard follow-up modality. Also, $60.0 \%$ of their patients were receiving anticoagulants which could have contributed to the incidence of gross hematuria. Finally, the authors stressed that the use of Radiation Therapy Oncology Group consensus guidelines could have led to the irradiation of larger bladder volumes, compared to other series.

A reasonable explanation about high late GU toxicity rate (grade $\geq 2: 46.1 \%$ ) shown by Syndikus and colleagues (19) may be due to the use of obsolete technique (60cobalt machine) as well as dose per fraction up to $3.1 \mathrm{~Gy}$ (mean: $2.76 \mathrm{~Gy}$ ).

In three studies, the percentages of severe late GU toxicity were comparable (11.0-15.0\%) $(22,25,27)$. All these authors prescribed in both adjuvant and salvage treatments a daily dose lower than 3.0 Gy on the prostate bed (range=2.5-2.9 Gy) using advanced treatment techniques such as IG-IMRT or VMAT with cone beam CT. The data on late toxicity reported by the other four studies was very encouraging, with a late GU toxicity rate ranging between $0 \%$ and $7.0 \%(20,23,26,32$, $35)$. The results achieved by Koukourakis and colleagues and Gladwish and co-workers are particularly interesting $(26,32)$. Despite the delivery of 3.4 and 3.0 Gy per fraction, respectively, late grade $\geq 2 \mathrm{GU}$ toxicity rates were only $0 \%$ and $3.0 \%$. It should be noted that the Greek group (26) used a 3DCRT technique, while all the other studies used IMRT. 
Probably, in this latter trial, the high-dose of amifostine positively impacted the results in terms of treatment tolerability.

About grade $\geq 2$ late GI toxicity, all studies showed a low incidence $(0-9.0 \%)$. The highest rate of this toxicity occurred in the study of Syndikus and his group (19) despite it not including irradiation of pelvic lymph nodes in the treatment field. These results are probably due to the RT technique, as mentioned above.

Homogeneous results were also observed for acute toxicity. In fact, grade $\geq 3$ acute GI and GU toxicity were recorded in $0 \%$ and $0-3 \%$ of patients, respectively. Based on these homogeneous results, it seems that prophylactic lymph nodes irradiation as well as concomitant androgen suppressive therapy did not worsen short term toxicity.

LC rate was reported by 3 trials $(19,26,35)$. The higher LC rate (3-year: $99.9 \%$ and 5-year: $94.9 \%$ ) was observed in Macchia and co-workers study despite the high percentage of patients with high-risk features (GS $\geq 7$ : 78.2\%; R1 resection: $84.7 \%$ ) enrolled in the trial and non-negligible percentage of patients with biochemical or local failure (salvage RT: $14.5 \%$ ) (35). An explanation of this excellent result may be the choice of administering a prophylactic irradiation on pelvic nodes combined with hormonal therapy in $80 \%$ of patients. Another excellent result was reported in Koukourakis and colleagues trial (26) despite the high percentage of patients with disease failure (salvage RT: $56.2 \%$ ) and high-risk Pca (GS $\geq 7: 54.2 \%$; $\mathrm{R} 1$ resection: $20.8 \%$ ) enrolled in the study. This result may be due to the higher dose per fraction (3.4 Gy in 15 fractions) compared to other studies, or irradiation of pelvic lymph nodes with HFRT (2.7 Gy/fraction) and combination with hormonal therapy in $47.9 \%$ of patients. Actuarial 5- and 10-year LC in Syndikus and colleagues trial were $69.0 \%$ and $54.0 \%$, respectively (19). This result was reported only for patients with local recurrence while data on patients treated with early RT were not reported. Also for this study, the use of a high dose per fraction $(2.76 \mathrm{~Gy})$ and combination with hormonal therapy could explain the high local control rate.

Actuarial long-term OS was reported in Syndikus and Macchia trials: $91.0 \%$ at 10 years (19) and $100 \%$ at 3 and 5 years (35), respectively. Four other trials with median follow-up 36.0 (20), 18.9 (23), 32.4 (25), and 48.0 months (32) reported excellent crude OS rates $(100 \%, 98.0 \%, 99.1 \%$, and $96.4 \%$, respectively). Delivery of a daily minimum dose of $2.5 \mathrm{~Gy}$ on the prostate bed and the choice to irradiate regional lymph nodes (as done in two of these trials $(23,25$, $35)$ ) in patients with high-risk disease and biochemical relapse could probably have had a positive impact on OS.

In the salvage setting, two studies reported $83.7-92.0 \%$ and $72.9-83.0 \%$ 1- and 2-year bRFS, respectively $(20,23)$. The better results recorded by Wong and colleagues (23) compared to Lee and co-workers (20) could be explained by the higher pathological tumor grade in the latter series (GS $\geq 7: 58.0 \%$ vs. $30.0 \%$, respectively). Three studies reported 3 -year bRFS ranging between $74.0 \%$ and $94.0 \%(20,34,35)$. As expected, the results were better in the adjuvant setting (94.0\%) (34) compared to the salvage setting (74.0-77.0\%) $(20,34)$. Four-year bRFS was reported in two studies ranging between $67.0 \%$ and $75.0 \%(25,33)$. This difference can by justified by the inclusion in the Kruser and colleagues' studies, of only patients treated for biochemical relapse (25). In a series of patients undergoing adjuvant $(85.5 \%)$ and salvage (14.5\%) RT, 86.5\% bRFS at 5-year was shown (35).

Other authors reported only crude bRFS rates $(83.0 \%$ (32), $85.4 \%$ (26), $100 \%$ (22)) with a median follow up of 25.0 , 41.0 , and 24.0 months, respectively $(22,26,32)$. The highest percentage of biochemical control was reported by Cozzarini and colleagues (22). It should be noted that their series was the one with the lowest median PSA before HFRT $(0.02$ $\mathrm{ng} / \mathrm{ml})$ compared to the other two trials $(26,32)$.

Considering the follow-up duration, also the results of Koukourakis and co-workers (26) seem positive, with $85.4 \%$ bRFS at median follow-up of 41 months. The high dose per fraction on the surgical bed (3.4 Gy per fraction) and the choice of an hypofractionated regimen to the pelvic lymph nodes (2.7 Gy per fraction) could have produced a positive impact on biochemical control, as previously mentioned for LC.

In conclusion, postoperative HFRT seems feasible and relatively well tolerated based on most published trials. However, it should be noted that: i) one trial showed a high 5-year grade $\geq 3$ late GU toxicity (18.1\%) (30), ii) two trials showed a high incidence of grade $\geq 2$ late GU toxicity $(46.1 \%$ and $66.1 \%)(19,33)$, iii) median follow-up between the analysed series was short (median: 30.0 months), iv) most series reported only crude data on late toxicity with a relevant risk of underestimating these effects. Therefore, in absence of clear data on radiation induced toxicity, in accordance with Hegemann and colleagues (42) and Höcht and coworkers (43) opinions, HFRT following radical prostatectomy should be used only in clinical trials. Randomized trials comparing postoperative RT with standard fractionation versus HFRT seem justified.

\section{Conflicts of Interest}

No actual or potential conflicts of interest exist regarding this paper.

\section{References}

1 Mottet N, Bellmunt J, Briers E, Bolla M, Cornford P, De Santis M, Henry A, Joniau S, Lam T, Mason M.D, Matveev V, van der Poel H, van der Kwast T.H, Rouvière $\mathrm{O}$ and Wiegel T: EAUESTRO-SIOG Guidelines on prostate cancer. Part 1: Screening, diagnosis, and local treatment with curative intent. Eur Urol 71: 618-629, 2017. 
2 NCCN Clinical Practice Guidelines in Oncology (NCCN Guidelines). Prostate cancer version 2, 2017. Available at http://www.nccn.org/professionals/physiciangls/pdf/prostate.pdf. Accessed on 6th November 2017.

3 Epstein JI, Zelefsky MJ, Sjoberg DD, Nelson JB, Egevad L, Magi-Galluzzi C: A Contemporary Prostate Cancer Grading System: A Validated Alternative to the Gleason Score. Eur Urol 69: 428-435, 2016.

4 Stephenson AJ, Scardino PT, Eastham JA, Bianco FJ Jr., Dotan ZA, Di Blasio CJ, Reuther A, Klein EA and Kattan MW: Postoperative nomogram predicting the 10 -year probability of prostate cancer recurrence after radical prostatectomy. J Clin Oncol 23: 7005-7012, 2005.

5 Thompson IM, Tangen CM, Paradelo J, Lucia MS, Miller G, Troyer D, Messing E, Forman J, Chin J, Swanson G, CanbyHagino E and Crawford ED: Adjuvant Radiotherapy for Pathological T3N0M0 Prostate Cancer Significantly Reduces Risk of Metastases and Improves Survival: Long-Term Follow up of a Randomized Clinical Trial. J Urol 181: 956-962, 2009.

6 Bolla M, van Poppel H, Collette L, van Cangh P, Vekemans K, Da Pozzo L, de Reijke TM, Verbaeys A, Bosset JF, van Velthoven R, Marechal JM, Scalliet P, Haustermans K and Pierart M, European Organization for Research, Treatment of Cancer: Postoperative radiotherapy after radical prostatectomy: a randomised controlled trial (EORTC trial 22911). Lancet 366: 572-578, 2005.

7 Wiegel T, Bottke D, Steiner U, Siegmann A, Golz R, Storkel S, Willich N, Semjonow A, Souchon R, Stockle M, Rube C, Weissbach L, Althaus P, Rebmann U, Kalble T, Feldmann HJ, Wirth M, Hinke A, Hinkelbein W and Miller K: Phase III postoperative adjuvant radiotherapy after radical prostatectomy compared with radical prostatectomy alone in pT3 prostate cancer with postoperative undetectable prostate-specific antigen: ARO 96-02/AUO AP 09/95. J Clin Oncol 27: 2924-2930, 2009.

8 Ost P, Cozzarini C, De Meerleer G, Fiorino C, De Potter B and Briganti A: High-dose adjuvant radiotherapy after radical prostatectomy with or without androgen deprivation therapy. Int J Radiat Oncol Biol Phys 83: 960-965, 2012.

9 Katayama S, Habl G, Kessel K, Edler L, Debus J, Herfarth K and Sterzing F: Helical intensity-modulated radiotherapy of the pelvic lymph nodes with integrated boost to the prostate bed initial results of the PLATIN 3 Trial. BMC Cancer 14: 20, 2014.

10 Cozzarini C, Montorsi F, Fiorino C, Alongi F, Bolognesi A, Da Pozzo LF Guazzoni G, Freschi M, Roscigno M, Scattoni V, Rigatti $\mathrm{P}$ and Di Muzio N: Need for high radiation dose $(\geq 70$ Gy) in early postoperative irradiation after radical prostatectomy: a single-institution analysis of 334 high-risk, node-negative patients. Int J Radiat Oncol Biol Phys 75: 966-974, 2009.

11 Brenner DJ and Hall EJ: Fractionation and protraction for radiotherapy of prostate carcinoma. Int J Radiat Oncol Biol Phys 43: 1095-1101, 1999.

12 Yeoh EE, Botten RJ, Butters J, Di Matteo AC, Holloway RH and Fowler J: Hypofractionated versus conventionally fractionated radiotherapy for prostate carcinoma: final results of phase III randomized trial. Int J Radiat Oncol Biol Phys 81: 1271-1278, 2011.

13 Incrocci L, Wortel RC, Alemayehu WG, Aluwini S, Schimmel E, Krol S, van der Toorn PP, Jager Hd, Heemsbergen W, Heijmen B and Pos F: Hypofractionated versus conventionally fractionated radiotherapy for patients with localised prostate cancer (HYPRO): final efficacy results from a randomised, multicentre, open-label, phase 3 trial. Lancet Oncol 17: 1061-1069, 2016.
14 Dearnaley D, Syndikus I, Mossop H, Khoo V, Birtle A, Bloomfield D, Graham J, Kirkbride P, Logue J, Malik Z, Money-Kyrle J, O'Sullivan JM, Panades M, Parker C, Patterson H, Scrase C, Staffurth J, Stockdale A, Tremlett J, Bidmead M, Mayles H, Naismith O, South C, Gao A, Cruickshank C, Hassan $\mathrm{S}$, Pugh J, Griffin $\mathrm{C}$ and Hall E; CHHiP Investigators: Conventional versus hypofractionated high-dose intensitymodulated radiotherapy for prostate cancer: 5-year outcomes of the randomised, non-inferiority, phase $3 \mathrm{CHHiP}$ trial. Lancet Oncol 17: 1047-1060, 2016.

15 Ippolito E, Guido A, Macchia G, Deodato F, Giaccherini L, Farioli A, Arcelli A, Cuicchi D, Frazzoni L, Cilla S, Buwenge M, Mantini G, Alitto AR, Nuzzo M, Valentini V, Ingrosso M, Morganti AG and Fuccio L: Predictive Factors of Late-onset Rectal Mucosal Changes After Radiotherapy of Prostate Cancer. In Vivo 31: 961-966, 2017.

16 Kunkler IH, Audisio R, Belkacemi Y, Betz M, Gore E, Hoffe S, Kirova Y, Koper P, Lagrange JL, Markouizou A, Pfeffer R and Villa S; SIOG Radiotherapy Task Force: Review of current best practice and priorities for research in radiation oncology for elderly patients with cancer: the International Society of Geriatric Oncology (SIOG) task force. Ann Oncol 25: 2134-2146, 2014.

17 Suy S, Oermann E, Hanscom H, Lei S, Vahdat S, Yu X, Park HU, Chen V, Collins BT, McGeagh K, Dawson N, Jha R, Azumi N, Dritschilo A, Lynch J and Collins SP: Histopathologic effects of hypofractionated robotic radiation therapy on malignant and benign prostate tissue. Technol Cancer Res Treat 9: 583-587, 2010.

18 Krause S, Sterzing F, Neuhof D, Edler L, Debus J and Herfarth $\mathrm{K}$ : Hypofractionated helical intensity-modulated radiotherapy of the prostate bed after prostatectomy with or without the pelvic lymph nodes - the PRIAMOS trial. BMC Cancer 12: 504, 2012.

19 Syndikus I, Pickles T, Kostashuk E and Sullivan LD: Postoperative radiotherapy for stage pT3 carcinoma of the prostate: improved local control. J Urol 155: 1983-1986, 1996.

20 Lee LW, Mc Bain CA, Swindell R, Wylie JP, Cowan RA and Logue JP: Hypofractionated Radiotherapy as Salvage for Rising Prostate-specific Antigen after Radical Prostatectomy. Clin Oncol 16: 517-522, 2004.

21 Cozzarini C, Fiorino C, Di Muzio N, Alongi F, Broggi S, Cattaneo M, Montorsi F, Rigatti P, Calandrino R and Fazio F: Significant reduction of acute toxicity following pelvic irradiation with Helical Tomotherapy in patients with localized prostate cancer. Radiother Oncol 84: 164-170, 2007.

22 Cozzarini C, Fiorino C, Di Muzio N, Valdagni R, Salonia A, Alongi F, Broggi S, Guazzoni G, Montorsi F, Rigatti P, Calandrino $\mathrm{R}$ and Fazio F: Hypofractionated adjuvant radiotherapy with helical Tomotherapy after radical prostatectomy: Planning data and toxicity results of a Phase I-II study. Radiother Oncol 88: 26-33, 2008.

23 Wong WG, Palazzi-Churas KL, Jarrard DF, Paolone DR, Graf AK, Hedican SP, Wegenke JD and Ritter MA: Salvage hypofractionated radiotherapy for biochemically recurrent prostate cancer after radical prostatectomy. Int $\mathrm{J}$ Radiation Oncology Biol Phys 70: 449-455, 2008.

24 Alongi F, Fiorino C, Cozzarini C , Broggi S, Perna L, Cattaneo GM, Calandrino R and Di Muzio N: IMRT significantly reduces acute toxicity of whole-pelvis irradiation in patients treated with post-operative adjuvant or salvage radiotherapy after radical prostatectomy. Radiother Oncol 93: 207-212, 2009. 
25 Kruser TJ, Jarrard DF, Graf AK, Hedican SP, Paolone DR, Wegenke JD, Liu G, Geye HM and Ritter MA: Early hypofractionated salvage radiotherapy for post-prostatectomy biochemical recurrence. Cancer 117: 2629-2636, 2011.

26 Koukourakis MI, Papadopoulou A, Abatzoglou I, Panteliadou M, Sismanidou $\mathrm{K}$ and Touloupidis $\mathrm{S}$ : Postoperative pelvic hypofractionated accelerated radiotherapy with cytoprotection (HypoARC) for high-risk or recurrent prostate cancer. Anticancer Res 32: 4561-4568, 2012.

27 Alongi F, Cozzi L, Fogliata A, Iftode C, Comito T, Clivio A, Villa E, Lobefalo F, Navarria P, Reggiori G, Mancosu P, Clerici E, Tomatis S, Taverna G, Graziotti $P$ and Scorsetti M: Hypofractionation with VMAT versus 3DCRT in Postoperative Patients with Prostate Cancer. Anticancer Res 33: 4537-4544, 2013.

28 Ippolito E, Cellini N, Digesù C, Cilla S, Mantini G, Balducci M, Di Lallo A, Deodato F, Macchia G, Massaccesi M, Mattiucci GC, Tagliaferri L, Piermattei A, Cuscunà D and Morganti AG: Postoperative intensity-modulated radiotherapy with simultaneous integrated boost in prostate cancer: A doseescalation trial. Urol Oncol 31: 87-92, 2013.

29 Massaccesi M, Cilla S, Deodato F, Digesù C, Macchia G, Caravatta L, Ippolito E, Picardi V, Ferro M, Mignogna S, Mattiucci GC, Valentini V, Piermattei A and Morganti AG: Hypofractionated Intensity-modulated radiotherapy with simultaneous integrated boost after radical prostatectomy: preliminary results of a phase II Trial. Anticancer Res 33: 2785-2790, 2013.

30 Cozzarini C, Fiorino C, Deantoni C, Briganti A, Fodor A, La Macchia Mariangela, Chiorda BN, Rancoita PMV, Suardi N, Zerbetto F, Calandrino R, Montorsi F and Di Muzio N: Higherthan-expected Severe (Grade 3-4) Late Urinary Toxicity After Postprostatectomy Hypofractionated Radiotherapy: A Singleinstitution Analysis of 1176 Patients. Eur Urol 66: 1024-1030, 2014.

31 Katayama S, Striecker T, Kessel K, Sterzing F, Habl G, Edler L, Debus J and Herfarth K: Hypofractionated IMRT of the prostate bed after radical prostatectomy: acute toxicity in the PRIAMOS1 trial. Int J Radiat Oncol Biol Phys 90: 926-933, 2014.

32 Gladwish A, Loblaw A, Cheung P, Morton G, Chung H, Deabreu A, Pang G and Mamedov A: Accellerated hypofractioned postoperative radiotherapy for prostate cancer: A prospective phase I/II study. Clin Oncol (R Coll Radiol) 27: 145-152, 2015.

33 Lewis SL, Patel P, Song H, Freedland SJ, Sigrun B, Oh D, Palta M, Yoo D, Oleson J and Salama JK: Image guided hypofractionated postprostatectomy intensity modulated radiation therapy for prostate cancer. Int J Radiat Oncol Biol Phys 94: 605-611, 2016.

34 Fersino S, Tebano U, Mazzola R, Giaj-Levra N, Ricchetti F, Di Paola G, Fiorentino A, Sicignano G, Naccarato S, Ruggieri R, Cavalleri $S$ and Alongi F: Moderate hypofractionated postprostatectomy volumetric modulated arc therapy with daily image guidance (VMAT-IGRT): A mono-institutional report on feasibility and acute toxicity. Clin Genitourin Cancer 15: e667e673, 2017.
35 Macchia G, Siepe G, Capocaccia I, Nguyen NP, Schiavina R, Cammelli S, Guerri S, Arcelli A, Buwenge M, Ntreta M, Cilla S, Valentini V, Deodato F and Morganti AG: Hypofractionated postoperative IMRT in prostate carcinoma: A Phase I/II Study. Anticancer Res 37: 5821-5828, 2017.

36 Sineshaw HM, Gray PJ, Efstathiou JA and Jemal A: Declining use of radiotherapy for adverse features after radical prostatectomy: results from the national cancer data base. Eur Urol 68: 768-774, 2015.

37 Leyh-Bannurah SR, Gazdovich S, Budaus L: Population-based external validation of the updated 2012 Partin tables in contemporary North American prostate cancer patients. Prostate 77: 105-113, 2016.

38 Gandaglia G, Briganti A, Clarke N, Karnes RJ, Graefen M, Ost P, Zietman AL and Roach M 3rd: Adjuvant and salvage radiotherapy after radical prostatectomy in prostate cancer patients. Eur Urol 72: 689-709, 2017.

39 Pound CR, Partin AW, Eisenberger MA, Chan DW, Pearson JD and Walsh PC: Natural history of progression after PSA elevation following radical prostatectomy. JAMA 271: 15911597, 1999.

40 King CR and Spiotto MT: Improved outcomes with higher doses for salvage radiotherapy after prostatectomy. Int J Radiat Oncol Biol Phys 71: 23-27, 2008.

41 Lewis SL, Patel PR, Palta M, Yoo DS and Salama JK: In reply to Fiorino and Cozzarini. Int J Radiat Oncol Biol Phys 94: 860$861,2016$.

42 Hegemann N-S, Guckenberger M, Belka C, Ganswindt U, Manapov $\mathrm{F}$ and Li M: Hypofractionated radiotherapy for prostate cancer. Radiat Oncol 9: 275, 2014.

43 Höcht S, Aebersold DM, Albrecht C, Böhmer D, Flentje M, Ganswindt U, Hölscher T, Martin T, Sedlmayer F, Wenz F, Zips $\mathrm{D}$ and Wiegel T: Hypofractionated radiotherapy for localized prostate cancer. Strahlenther Onkol 193: 1-12, 2017. 